\title{
Theoretical Study of Several
}

Oscillator Strengths and Lifetimes of Germanium, Thallium and Bismuth. Measures of Some Relative Transition Probabilities

Cite as: AIP Conference Proceedings 1058, 152 (2008); https://

doi.org/10.1063/1.3026428

Published Online: 27 October 2008

A. Alonso-Medina, C. Colón, A. Zanón, J. L. Montero, F. Fernández Martínez, and C. Rivero

\section{ARTICLES YOU MAY BE INTERESTED IN}

\section{Energy Levels of Germanium, GeI through Ge XXXII}

Journal of Physical and Chemical Reference Data 22, 1213 (1993); https://

doi.org/10.1063/1.555929

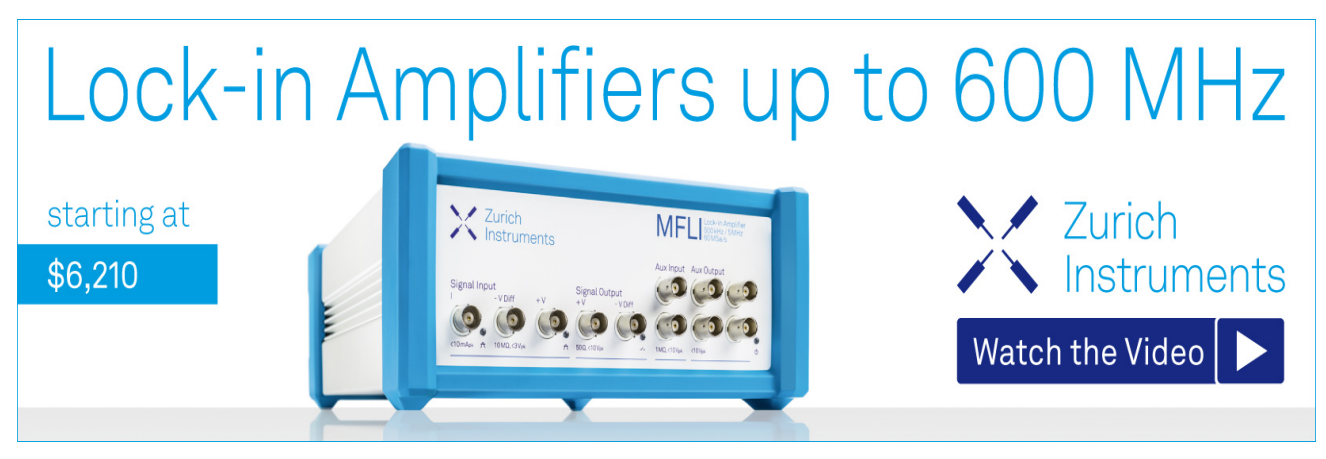




\title{
Theoretical Study of Several Oscillator Strengths and Lifetimes of Germanium, Thallium and Bismuth. Measures of Some Relative Transition Probabilities
}

\author{
A. Alonso-Medina ${ }^{\mathrm{a}}$, C. Colón ${ }^{\mathrm{a}}$, A. Zanón ${ }^{\mathrm{b}}, \mathrm{J} . \mathrm{L}$. Montero $^{\mathrm{c}}$, F. Fernández \\ Martínez $^{\mathrm{c}}$ and C. Rivero ${ }^{\mathrm{d}}$ \\ ${ }^{a}$ Dpto. de Física Aplicada. EUITI. Universidad Politécnica de Madrid (UPM) \\ ${ }^{b}$ Dpto. de Matemática Aplicada. EUITI. UPM \\ 'Dpto. de Quimica Industrial y Polimeros . EUITI.UPM \\ ${ }^{\natural}$ Dpto. de Tecnologias Aplicadas a la Telecommicación ETSIT. UPM \\ Madtrid Spain
}

\begin{abstract}
Transitions probabilities for several lines arising from excited levels of $\mathrm{Ge} \mathrm{I,} \mathrm{Bi} \mathrm{I,} \mathrm{and}$ Tl I have from determined from emission lines intensities in a hollow-cathode discharge. These values were put on an absolute scale by using, were possible, the experimental lifetimes published by others authors. Oscillator strengths for several lines interest arising from some configurations and some levels radiative lifetimes of these elements have been calculated.
\end{abstract}

Keywords: Transitions Probabilities, Oscillator strengths, radiative lifetimes.

PACS: 31.15. A-, 31.15.ag., 32.70.Cs, 32.70.Fw.

\section{PROCEDURE, RESULTS AND DISCUSSION}

The presence of Thallium, Bismuth and Germanium in stellar spectra has been reported in a few different types of stars [1-3]. Data on atomic properties are relevant not only for spectroscopy; these values are also of interest in a variety of other fields in physics and technology. Calculations of oscillator strength for different transitions in Thallium, Bismuth and Germanium has been the subject of numerous theoretical studies [4-8].

In this work a complete study of atomic parameters of different species of these elements has been made. We have obtained theoretical values of oscillator strengths in intermediate coupling (IC) using ab initio relativistic Hartree-Fock (HFR) calculations. For the IC calculations we used the standard method of least-square fitting of experimental energy levels by means of computer codes from Cowan [9].

In this way we obtained the LS composition of each level and the degree of configuration mixing, when we consider their interaction. To provide level energy for our calculation we have used the Tables of Moore [10]. 
TABLE. Oscillator Strengths, Transition Probabilities and radiative lifetimes of Ge I, Bi I and T1 I.

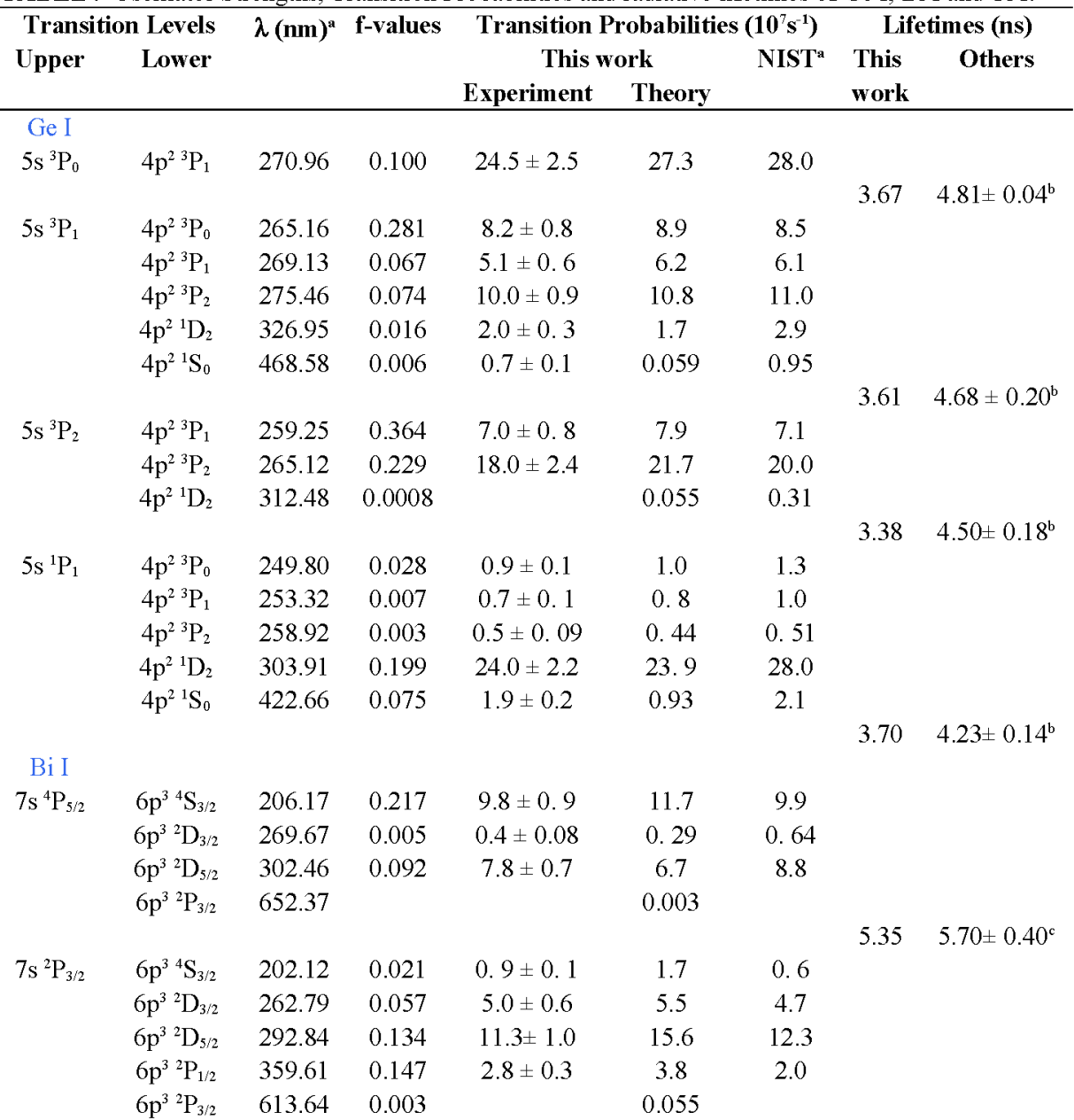

3.76

Tl I

\begin{tabular}{|c|c|c|c|c|c|c|c|}
\hline \multirow[t]{2}{*}{$8 s^{2} S_{1 / 2}$} & $6 p^{2} \mathrm{P}_{1 / 2}$ & 258.01 & 0.020 & $2.0 \pm 0.2$ & 2.0 & $1.7^{\mathrm{d}}$ & 1.8 \\
\hline & $6 \mathrm{p}^{2} \mathrm{P}_{3 / 2}$ & 322.97 & 0.018 & $1.9 \pm 0.2$ & 2.3 & $2.2^{\mathrm{d}}$ & 1.7 \\
\hline \multirow[t]{2}{*}{$9 \mathrm{~s}^{2} \mathrm{~S}_{1 / 2}$} & $6 p^{2} P_{1 / 2}$ & 231.60 & 0.007 & $0.70 \pm 0.09$ & 0.82 & $0.74^{\mathrm{d}}$ & 0.78 \\
\hline & $6 \mathrm{p}^{2} \mathrm{P}_{3 / 2}$ & 282.62 & 0.006 & $0.91 \pm 0.09$ & 1.0 & $0.94^{\mathrm{d}}$ & 0.80 \\
\hline \multirow[t]{2}{*}{$10 \mathrm{~s}^{2} \mathrm{~S}_{1 / 2}$} & $6 p^{2} \mathrm{P}_{1 / 2}$ & 220.71 & 0.004 & $\begin{array}{l}1.1 \pm 0.1 \\
1.3 \pm 0.1^{\mathrm{e}}\end{array}$ & 0.59 & $0.39^{\mathrm{d}}$ & \\
\hline & $6 \mathrm{p}^{2} \mathrm{P}_{3 / 2}$ & 266.56 & 0.003 & $\begin{array}{c}0.55 \pm 0.06 \\
0.60 \pm 0.06^{\mathrm{c}}\end{array}$ & 0.60 & $0.50^{\mathrm{d}}$ & 0.57 \\
\hline \multirow[t]{2}{*}{$6 \mathrm{~d}^{2} \mathrm{D}_{3 / 2}$} & $6 p^{2} P_{1 / 2}$ & 276.79 & 0.422 & $13.6 \pm 1.2$ & 18.4 & $16.5^{\mathrm{d}}$ & 12.6 \\
\hline & $6 p^{2} \mathrm{P}_{3 / 2}$ & 352.94 & 0.037 & $1.9 \pm 0.2$ & 2.0 & $2.2^{\mathrm{d}}$ & 2.2 \\
\hline
\end{tabular}


Also in this work we present experimental values for several lines corresponding to different transitions of T1 I, T1 II, Ge I, Ge II, Bi I and Bi II. Relative values have been obtained from measures of emission line intensities in hollow cathode lamp discharges operating with a typically current of $10 \mathrm{~mA}$.

The wavelengths of the measured transitions are the UV, Visible and IR. The infrared spectra were obtained using a Czerny-Turner monochromator (Digikrom CVI). A IHR55 Jobin-Ibon monochromator was used to obtain the visible and UV spectrum. We used in both cases a CCD to detect the optical signal.

We have used two different methods in order to place data on an absolute scale. We have use the experimental lifetimes present in the bibliography and using line-strength sum rules applied to our relativistic calculations. Our results have been compared with the values presents in the literature $[8,11,12]$.
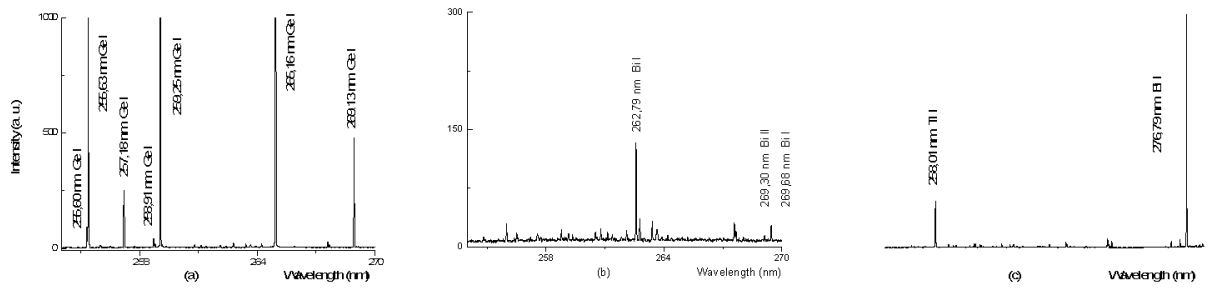

FIGURE 1. Emission lines of Ge I, Bi I, Bi II and Tl II (hollow-cathode lamp filled with neon).

\section{ACKNOWLEDGMENTS}

This work has been supported by the project CCG07-UPM/ESP-1632 of the TECHNICAL UNIVERSITY OF MADRID (UPM). Support to the lines of UPM investigation groups included in the IV PRICIT of the CAM (Comunidad Autónoma de Madrid), SPAIN.

\section{REFERENCES}

1. S. Vennes, P. Chayer and J. Dupuis, $A p J$ 622, L121-L124 (2005).

2. G. M. Wahlegren, Proccedings IAU Symposium 224, 291-299 (2004).

3. S. Goriely and L. Siess, $A \& A 378$, L25-L28 (2001).

4. L. Caiyan, U. Berzinsh, R. Zerne and S. Swanberg, Phys. Rev. A 52, 1936-1941 (1995).

5. E. Biemont, C. Lynga, Z. S. Li, S. Svanberg, H. P. Garmir and P. S. Doidge, MNRAS 303, $721-724$ (1999).

6. E. Biemont, P. Palmeri, P. Quinet, Z Dai, S. Svanberg and H. L. Xu, J. Phys B. 38, 3547-3558 (2005).

7. U. I . Safronova, M. S. Safronova and W. R. Johnson, Phys. Rev. A 71, 052506-18 (2005).

8. A. Alonso-Medina, An, Phys. 92, 71-84 (1996a).

9. R. D. Cowan, Theory of Atomic Structure and Spectra, edited by University Press, Los Angeles, 1981.

10. C. E. Moore, in Atomic Energy Levels, edited by NBS 467, Washington D. C., 1958.

11. A. Alonso-Medina, JQSRT 56, 557-562 (1996b).

12. A. Alonso-Medina, J. Phys B. 30, 1377-1384 (1997). 